\title{
A POÉTICA E SUAS POTÊNCIAS - A LEITURA DE UM ATOR
}

RESUMO

Este artigo apresenta as potências de leitura e interpretação da "Poética" de Aristóteles, sob a perspectiva do trabalho do ator. Buscamos explicitar tal possibilidade de leitura partindo de uma perspectiva histórica sobre a difusão e interpretação dessa obra, bem como pelo cruzamento de alguns conceitos Aristotélicos com alguns pontos das obras de teóricos modernos do trabalho do ator.

Palavras-chave:

Ator; Aristóteles, poética. 


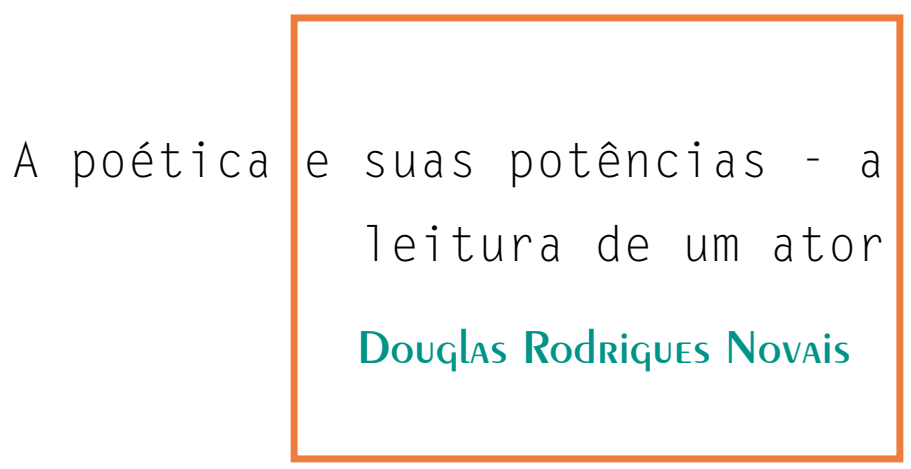

Apresentarei a seguir as origens de um estudo que desenvolvi recém-formado na graduação em artes cênicas e que levaram, posteriormente, ao desenvolvimento da tese de doutorado "A Poesia do Ator - o ofício e a formação do intérprete sob uma perspectiva Aristotélica". O conteúdo desse artigo é resultado de uma investigação sobre A Poética de Aristóteles e de um cruzamento desse estudo com a teoria de alguns dos principais teóricos modernos do trabalho e formação do ator.

Diversas questões aqui apontadas foram desenvolvidas na tese, de modo que optei por preservar o caráter panorâmico desse artigo a fim de destacar, sobretudo, as potências de leitura e interpretação da poética de Aristóteles.

Tal escolha se deve a uma impressão de que parece vigorar nos tempos atuais, uma ideia de que o conhecimento histórico tem uma função independente da prática concreta em que consiste o mesmo campo estudado por essa historiologia - por exemplo, que a história da arquitetura não interfere nas técnicas de construção utilizadas nos dias de hoje, que as práticas médicas antigas em nada contribuem com a medicina atual; todas elas não serviriam senão como fábulas a serem guardadas num canto do cérebro separado daquele departamento que tomaria decisões e agiria na vida real, relegadas, no fim das contas, à formação de professores de história, de pessoas que contam boas histórias da arquitetura, da medicina etc. ou que, pior ainda, ostentam conhecimento pelo mero ostentar.

Um abismo, em outras palavras, entre teoria (ou história) e prática (ou atualidade) derivaria dessa concepção. Com o intuito de não incidir nesse equívoco, proponho a seguir um breve apanhado histórico 
da Poética de Aristótelespara articular alguns pontos da prática teatral contemporânea à luz desses poucos dados, com o intuito não de focar nesses paralelismos, mas de revelar, por meio das já conhecidas teorias modernas sobre o trabalho do ator, os caminhos que levaram à construção da citada pesquisa de doutorado.

\subsection{As Origens}

Conheci a Poética de Aristóteles em uma aula de história do teatro em meu primeiro ano de formação universitária. O professor falava de algo que nos parecia ser um totem ressequido, uma ferramenta obsoleta da criação dramatúrgica. A idade daquele documento não nos inspirava respeito, mas antes sugeria um caráter anacrônico e dispensável, como as folhas de xerox que o comportavam.

Não sabia eu que a Poética de Aristóteles é considerada uma obra fundamental da teoria da arte, que não são poucos os autores que a ela atribuem o título de principal obra sobre estética ocidental e que, a despeito de críticas sofridas no período clássico, não houve quem abalasse sua autoridade ao longo de vinte e três séculos - séculos, não anos.

O registro dessa obra se deu entre os anos 335 a.C. e 323a.C., e a primeira tradução para o português, anônima, data de 1779. Mais tarde, em 1789, foi publicada a tradução de Ricardo Raimundo Nogueira, A Poética de Aristóteles, traduzida diretamente do grego (Lisboa, Régia Oficina Tipográfica).

\footnotetext{
${ }^{1}$ Eudoro de Sousa publicou as seguintes edições: 1951 (Lisboa: Guimarães), com introdução e índices, 1966 (Porto Alegre: Globo), com prefácio, introdução, comentário e apêndices, 1973 (São Paulo: Abril), na primeira versão, coleção Os Pensadores, glossário, 1986 (Lisboa: Imprensa nacional/Casa da moeda), com prefácio, introdução, comentário e apêndices, 1992 (São Paulo: ArsPoetica) original grego e tradução.

${ }^{2}$ As edições atuais baseiam-se em traduções dos seguintes manuscritos:

- Dois manuscritos gregos: o Parisinus 1741, que data do século X e é o manuscrito principal, e o Ricardianus 46, datado do século XIV, que, embora mutilado, complementa o Parisinus 1741;

- Um manuscrito árabe: a Versão Árabe, do século X, que remete ao texto grego através de uma versão siríaca;

- Dois manuscritos latinos: o Toletanus, escrito em torno de 1280, e oEtonensis, de 1300, os quais encontram-se pela tradução latina, efetuada em 1278 por Guilherme de Moerbeke.

${ }^{3}$ Essa probabilidade é indicada pelo que diz o próprio Aristóteles no capítulo VI: "Da arte de imitar em hexâmetros e da comédia trataremos adiante" [ARISTÓTELES. Poética. Tradução de Eudoro de Sousa. (1449 b21)].
}

O principal tradutor da obra para o português é Eudoro de Sousa, responsável por diversas publicações da obra. ${ }^{1}$

As edições recentes baseiam-se, sobretudo, na tradução manuscrita de cinco documentos fundamentais escritos nas línguas grega, latina e árabe. ${ }^{2}$

Pelas datas em que foram produzidas tais traduções (1200-1700) é possível inferir que o texto da Poética de Aristóteles não foi especialmente difundido durante a Antiguidade. Segundo Segismundo Spina, até mesmo Horácio, "cuja Ars Poética é visivelmente inspirada na do filósofo grego, não demonstra havê -la conhecido diretamente, mas através de um peripatético do séc. III, o gramático de Paros, Neoptolemo" (SPINA, 1995, p. 47).

Spina afirma ainda que, esquecida durante vários séculos, A Poética de Aristóteles foi traduzida para o siríaco no sec. VI, altura em que já se havia perdido a sua segunda parte, que devia, segundo todas as probabilidades, ser constituída de uma teoria da comédia. ${ }^{3}$

Somente no Renascimento, e principalmente na Itália, ao longo do séc. XVI, a Poética se tornou objeto de curiosidade e de pesquisa. $\mathrm{O}$ surgimento da imprensa e a subsequente difusão da obra em larga escala permitiu que abundassem a partir de então as traduções, estudos e comentários a seu respeito, em áreas diversas como a Linguística, Filosofia e o Teatro.

\subsection{Teatro e a Poética}

De como a poética foi compreendida no Renascimento

A Poética é vista usualmente como um tratado que versa sobre os processos de composição na arte. No caso específico de Aristóteles, sua Poética trata evidentemente dos processos de construção da tragédia, e foi dessa maneira que o texto foi lido durante todo o começo da época moderna influenciando o renascimento do gênero trágico no século de ouro espanhol e, é claro, de Shakespeare. 
De como a Poética se fundiu na prática europeia

Segundo Mauro Toledo (2005), a influência da Poética se estende do já citado século XVII, com os trágicos franceses, até chegar ao século XVIII, quando passa por várias releituras, especialmente a de Diderot, na França, e Lessing, na Alemanha. Dessas releituras, surge um novo gênero, o drama burguês, que paulatinamente ocupa o lugar da tragédia. No século XVIII, emblematicamente, a tragédia, enquanto gênero dramático desaparece. "Mas, se por um lado assistimos ao paulatino desaparecimento do gênero trágico, por outro, testemunhamos a redescoberta do trágico visto agora não como mero gênero literário, mas como matéria de especulação filosófica" (TOLEDO, 2005, p. 8), como se encontra, por exemplo, na obra de Schelling ou de Nieztche.

\section{Do modo como se entende hoje em dia a Poética}

Em grande parte, no interior da academia europeia, teatro se tornou sinônimo de literatura dramática por conta de um modo específico de leitura da Poética que foi se consolidando, a rigor, a partir do classicismo francês. De uma maneira geral, atribuise a Aristóteles uma visão do acontecimento cênico enquanto "espetáculo" como sendo algo inferior se comparado ao texto da tragédia propriamente dito.

Não é possível, no entanto, atribuir a Aristóteles a avaliação do espetáculo como condição menor do teatro em comparação com a dramaturgia propriamente dita. Pelo contrário, como afirma no último capítulo da Poética, "a tragédia é superior porque contém todos os elementos da epopeia (chega até a servir-se do metro épico), e demais, o que não é pouco, a melopeia e o espetáculo cênico, que acrescem a intensidade dos prazeres que lhe são próprios" (ARISTÓTELES:1966. Cap. XXVII, 1462 a15).

O italiano Marco de Marinis mostra que essa acepção da primazia do texto sobre o espetáculo não se sustenta na Poética de Aristóteles em si, mas em preocupações específicas do universo classicista francês, enviesando a leitura de Aristóteles nessa direção. Segundo Marco de Marinis, o filósofo de Estagira tinha outra perspectiva: a de buscar valorizar o estatuto do texto em uma sociedade amante do espetáculo, mas ainda assim considerando o espetáculo como razão de ser do teatro. Em lugar de propor a negação do espetáculo, Aristóteles teria antes argumentado em favor do reconhecimento da especificidade do texto dramatúrgico, isto é, da sua definição enquanto obra poética dotada de vocação teatral (BRANDÃO, 2006, p. 113)

Por essa perspectiva, é possível verificar que, por um lado, a história da pesquisa teatral ocidental pós-renascentista tem sido intimamente relacionada à pesquisa da dramaturgia; mas, por outro, se comparo esse quadro ao panorama da produção atual, observo que o teatro de nosso tempo supõe, ao contrário, o aspecto espetacular como uma condição decisiva da sua existência.

Se, nos tempos que correm, o espetáculo continua sendo o motor da engrenagem teatral, seria possível retornarmos à Poética de Aristóteles buscando ali aspectos universais que iluminem os caminhos da construção dos artistas do teatro de hoje? Será possível que a raiz da cena contemporânea tenha algo em comum com o que importava ao espetáculo quatro séculos antes de Cristo?

\section{Da reconfiguração da figura do encenador}

O nascimento do teatro moderno marcou uma ruptura com a concepção do teatro fundada na centralidade do texto. Um dos grandes marcos dessa era moderna do teatro é o desenvolvimento da função do encenador. A ele cabe dar unidade e coesão ao espetáculo, apontando ou determinando os caminhos da encenação, sendo também ele, muitas vezes, quem coordena o grupo, no aspecto de sua gestão. É neste momento que surgem nomes como Stanislavski, Meyerhold, Jacques Coupeau, Grotowski e Bertold Brecht entre tantos outros; grandes encenadores do teatro moderno que têm em comum o fato de suas pesquisas estarem em grande medida nas mãos, no corpo, no ser e na ação dos atores, o que fez com que muitos desses diretores fossem também pesquisadores da arte da interpretação. 
Da mudança de olhar quanto ao ator nos dias de hoje

Olhando para a história do teatro, podemos encontrar umas tantas orientações implícitas aos atores, aqui e ali, nas obras antigas do teatro. Em "Prometeu Acorrentado" de Ésquilo, por exemplo, é dito que "a técnica é, sem dúvida alguma, mais fraca que a necessidade" (ÉSQUILO, 1977, p. 514). Hamlet, de Shakespeare, diz-nos:

Acomoda o gesto à palavra e a palavra ao gesto, tendo sempre em mira não ultrapassar a modéstia da natureza, porque o exagero é contrário ao propósito da representação, cuja finalidade sempre foi, e continuará sendo, como que apresentar o espelho à natureza. (SHAKESPEARE, 1978)

Mas nada disso se compara ao enorme volume de produções sobre o trabalho de ator que se produziu na modernidade. É com o grande trabalho realizado por Stanislavski na construção do seu método, e que posteriormente culminaria no "Teatro Pobre" de Grotowski, que o ator passa a ser visto como figura central e essencial do teatro. A partir deste momento, então, é que se observa uma explosão de teorias e estudos voltados ao ator. A partir do impulso dado por Stanislavski, figuras importantes como Meyerhold, Artaud, Stela Adler, Eugenio Barba, Peter Brook, Adolphe Appia, Dullin, Julian Beck e Judith Malina, e Eugenio Kusnet elevam a pesquisa sobre o trabalho do ator a um patamar nunca antes visto na história ${ }^{4}$.

Esse conjunto de mudanças, especialmente se considerarmos as teorias de Brecht e seu Teatro Épico, Lehman e seu Teatro Pós-Dramático e Augusto Boal com seu Teatro do Oprimido, parecem conduzir a uma superação da teoria aristotélica. Como seria, no entanto, considerar esse movimento não como uma aniquilação, mas um replantio?

\footnotetext{
${ }^{4}$ Neste ponto, é fundamental citar o menos conhecido mas não menos importante brasileiro João Caetano, que, com suas "Lições Dramáticas", fundou a teoria para o ator brasileira.

${ }^{5}$ ARISTÓTELES, A Poética (Cap. I, 1447 a): “A epopeia e a poesia trágica, assim como a comedia, a poesia ditirâmbica, a maior parte da aulética e da citarística, consideradas em geral, todas se enquadram nas artes de imitação."
}

Os paralelos que apresento a seguir visam revelar os recônditos do pensamento Aristótelico presentes na Poética e que possam, ainda que brevemente, apontar orientações para o trabalho do ator.

\subsection{A arte do ator: paralelos entre os teóricos mo- dernos da interpretação e Aristóteles}

\section{Diderot e Aristóteles: a imitação}

Um pouco antes de Stanislavski, na França, Denis Diderot havia publicado um estudo, ainda rudimentar se comparado à obra de Stanislavski, intitulado "Paradoxo sobre o Comediante" no qual ele apontava as qualidades de um grande ator:

Que tenha muito discernimento; acho necessário que haja nesse homem um espectador frio e tranquilo; exijo dele, por consequência, penetração e nenhuma sensibilidade, a arte de tudo imitar, ou, o que dá no mesmo, uma igual aptidão para toda espécie de caracteres e papéis (DIDEROT, 1979, p. 354)

Ora, tal visão está plenamente de acordo com a visão aristotélica, uma vez que na Poética, escrita por volta de 330 anos antes de Cristo, já há a definição de que é o teatro uma arte da imitação ${ }^{5}$. E mais, em sua definição da tragédia, Aristóteles deixa claro que são as ações o centro da imitação.

\section{Stanislavski e Aristóteles: ação e finalidade}

O sistema de Stanislavsk por sua vez recebe, não sem razão, o nome de "Método das ações físicas". Estão Diderot, Aristóteles e Stanislavski a falar da mesma coisa, da essência do teatro, da essência da ação do ator.

Talvez passe despercebido também o fato de que existe, na concepção de Stanislavski, um fundamento muito próximo daquele aristotélico. Em sua A Preparação do Ator, ele diz "Em cena, não corram por correr, nem sofram por sofrer... Atuem sempre com um objetivo" (STANISLAVSKI, 1936, p.67 grifo nosso). 
A finalidade para Aristóteles é a causa principal da ação humana, é o meio pelo qual se define a ação. É essa concepção que aparece na icônica definição de tragédia, no capítulo VI de sua obra: "É, pois a tragédia, a imitação de uma ação de caráter elevado, completa e de certa extensão, em linguagem ornamentada... e que, suscitando o terror e a piedade, tem por fim a purificação dessas emoções." (ARISTÓTELES:1966. Cap. VI, 1449 b25)

\section{Artaud e Aristóteles: transe e catarse}

Outro grande expoente do teatro do início do século XX foi Antonin Artaud, ator, poeta, autor, dramaturgo e diretor que, em sua obra $O$ Teatro $e$ seu Duplo, propunha “(...) Um teatro que produza transes (...) que se dirija ao organismo com meios preciosos e com os mesmos meios que as músicas curativas de certos povos..." (ARTAUD, 1999, p. 23). Esse efeito curativo pode ser considerado, por analogia, com o efeito que a Catarse produziria no espectador, segundo a teoria Aristotélica. Para ele, a finalidade do teatro era a catarse, termo que não foi definido pelo filósofo e que, por conta disso, foi adornado com inúmeras interpretações. Entre os vários sentidos que o termo pode ter (religioso, psicológico, moral ou fisiológico/médico), destaca-se assim a possibilidade desse efeito "curativo" de certas emoções.

Brecht e Aristóteles - fábula e drama

Até mesmo Bertold Brecht, tradicionalmente conhecido pela oposição de seu Teatro Épico ante a concepção Aristotélica da criação dramatúrgica, mostra em seu Pequeno Organon para o Teatro haver pontos de concordância em suas visões do teatro, a começar pelo título da obra, emprestado do próprio compêndio de lógica e linguística aristotélico. Diz Brecht que “[a] fábula é, segundo Aristóteles - e nesse ponto pensamos identicamente -, a alma do drama" (BRECHT, 2005, p. 104).

Brecht está a se referir da passagem da Poética em que diz Aristóteles: Portanto o mito é como que o princípio e alma da tragédia. (ARISTÓTELES:1966 Cap. VI 1450 a35).
Eis aí uns poucos exemplos que nos mostram que Aristóteles e a sua Poética integram o cerne do debate acerca da produção teatral ainda na modernidade, e ainda por autores que, em suas linhas gerais, preferiram referir-se ao velho Estagirita como antiexemplo. Ademais, a possibilidade de extrair da Poética e da obra de Aristóteles orientações para o trabalho do ator deriva da própria forma da Poética:

Esse frenesi exegético explica-se em primeiro lugar pelas próprias características da Poética. Inúmeras vezes foram apontadas suas incoerências, suas contradições, suas lacunas, suas digressões e suas elipses... Portanto, qualquer que seja a explicação desse estado de fato, a obra de Aristóteles permite aos exegetas encontrar material para justificar as doutrinas mais diversas. (ROUBINE, 2003, p. 14)

Eis aí uns poucos exemplos que nos mostram que Aristóteles e a sua Poética integram o cerne do debate acerca da produção teatral ainda na modernidade, e ainda por autores que, em suas linhas gerais, preferiram referir-se ao velho Estagirita como antiexemplo. Ademais, a possibilidade de extrair da Poética e da obra de Aristóteles orientações para o trabalho do ator deriva da própria forma da Poética:

Pelo conjunto de elipses presentes na obra que nos possibilitam as mais diversas análises e teorias, podemos concluir que não é a Poética um documento morto e que parte do seu valor se compõe também de tudo aquilo que nela falta.

\subsection{De que Aristóteles não é mero objeto de apre- ciação histórica}

Por este breve retrospecto histórico, em que contextualizo a Poética, é possível identificar uma realidade inerente à evolução do teatro- e, por conseguinte, do próprio conhecimento humano como 
um todo: parece haver um elemento de permanência na evolução histórica do teatro, aquilo que chamamos a essência do objeto.

A nós, habitantes de um tempo em que a ideia de um progresso linear e cumulativo do conhecimento, representado pelas tecnologias, arraigou-se em nosso pensamento com força de uma verdade indubitável, vale questionarmo-nos quanto ao seguinte: servem-nos as obras de Aristóteles ou Platão, hoje, apenas como documentos históricos? Teriam esses homens falado apenas para os gregos, na situação grega, e não para nós?

Parece-me uma clara evidência que o nosso tempo não seja o soberano na produção do conhecimento, que não basta ver as outras épocas com os olhos da nossa, temos de ver a nossa com os olhos das outras, sob o risco de, em caso contrário, ficarmos cegos, perdendo o fio da continuidade da existência humana.

É forçoso que isso assim seja! Do contrário, como saber em qual momento eu deveria jogar todo o conhecimento adquirido na lata do lixo e recomeçar a construir meu conhecimento desde a estaca zero? Ninguém em sã consciência faria isso, pois a proximidade dos fatos iluminaria o absurdo e nos impediria. $\mathrm{O}$ absurdo de se descartar aquilo que de bom (e atual) existe em Stanislavski, em Artaud ou em Brecht também detém nossa mão contra um homicídio doloso. Ora, se podemos dar quatro passos até o início do século XX, por que nos negar a dar vinte até o IV a.C.?

o historicismo que cria este afunilamento e refere as ideias aos momentos e situações históricas tem de ser compensado por uma operação inversa, uma espécie de "desistoricismo", que julgue estas ideias não pelo momento onde surgiram, mas pelo que elas exigem e cobram de nós hoje. (CARVALHO, 1994, s/p)

Servindo-me das palavras desse filósofo, permito-me concluir com palavras de artista. Eis aí, então, em que este estudo busca ser útil a seus leitores: não um passeio por um museu, mas por um palácio a ser restaurado.
Sempre se esquece que o filosofo, tal como o poeta, é o portador de futuros entre nós e pode contar menos do que os outros com a participação de sua época. Filósofos e Poetas são contemporâneos de pessoas de um futuro longínquo e, tão logo, prescindam de agitar seu vizinho, não tem motivo algum para criar ordens e tirar conclusões em seu desenvolvimento, exceto aquelas compilações sistemáticas que lhe são necessárias para uma visão geral de sua situação e, que no entanto, são sempre destruídas de novo por eles mesmos em beneficio de seu progresso interior. (RILKE, 2007, p. 195) 


\section{REFERÊNCIAS}

ARISTÓTELES.Poética. Trad. Eudoro de Sousa, Porto Alegre, Globo, 1966. [tradução e extenso estudo].

ARTAUD, Antonin. O teatro e seu duplo. São Paulo: Martins Fontes, 1999.

BRECHT, Bertold. Estudos sobre teatro. Rio de Janeiro: Nova Fronteira, 2005.

BRANDÃO, Tania. "Artes Cênicas: Por uma metodologia da pesquisa histórica" In: CARREIRA, André, et al (Org.). Metodologia de pesquisa em Artes Cênicas. Memória ABRACE IX. Rio de Janeiro: 7 Letras, 2006.

CARVALHO, Olavo de. "Pensamento e Atualidade de Aristóteles". Transcrição de aula realizada no dia 15 de março de 1994 e publicada em http://www.olavodecarvalho. org/apostilas/pensaris1_1.htm

DIDEROT, Denis. Paradoxo sobre o comediante.Coleção Os Pensadores. São Paulo: Abril Cultura, 1979.

ÉSQUILO. Prometeu Acorrentado. Tradução de Daisi Malhadas \& Maria Helena de Moura Neves. Araraquara: UNESP / ILCSE, 1977, p. 514.

ROUBINE, Jean Jacques. Introdução às grandes teorias do teatro. Tradução André Telles. Rio de Janeiro: Jorge Zahar, 2003.

RILKE, Rainer Maria. Cartas do Poeta sobre a vida: a sabedoria de Rilke. Organização de UlrichBaer. Tradução de Milton Camargo Mota. Coleção Prosa. São Paulo: Martins, 2007.

SHAKESPEARE, William. Hamlet. Tradução de Carlos de Almeida Cunha Medeiros e Oscar Mendes. Rio de Janeiro: Nova Aguiar, 1978

SPINA, Segismundo. Introdução à poética clássica. São Paulo: Martins Fontes, 1995.

STANISLAVSKI, Constantin. A Preparação do Ator. Tradução: Pontes de Paula Lima. Rio de Janeiro: Civilização Brasileira, 1936.Trecho do ato III, cena II.

TOLEDO, Alexandre Mauro. Mímesis e tragédia na Poética de Aristóteles. Belo Horizonte: UFMG, 2005.

\section{Abstract}

This article presents the possibilities of reading and interpretation of Aristotle's "Poetics", from the perspective of the work of the actor. We seek to explain this possibility of reading from a historical perspective on the diffusion and interpretation of this work, as well as for the crossing of some Aristotelian concepts with some points of the works of modern theorists of the work of the actor. 